\section{Fórum: racionamento dos cuidados de saúde. Introdução}

\author{
Forum: rationing health care services. Introduction
}

\begin{abstract}
Explicit rationing of health care is one of the most important issues under debate in the academic and political fields in both developed and developing countries. The articles presented in this Forum provide an approach to some of the questions relating to this issue. The approach is multidisciplinary, covering complex ethical questions and the contribution of economics to the debate. The analyses reveal specificities associated with the shift from implicit approach for rationing of health care, traditionally dominant in health systems, to a systematic and explicit priority-setting method in general and the potential incompatibility between efficiency and equity objectives in health policy in particular. The Forum's reflections link directly to current worldwide discussions on the questions "Why ration health care?" and "How to ration health care?".
\end{abstract}

Delivery of Health Care; Health Systems; Health Planning
Micaela Moreira Pinho 1,2

A generalidade dos países com sistemas de saúde publicamente financiados enfrenta um problema comum - a insustentabilidade financeira do sistema de saúde. O crescimento continuado dos custos com a saúde a um ritmo superior ao da criação de riqueza põe em causa a viabilidade financeira dos sistemas de saúde e do estado de bem-estar social. Fatores como a rápida sofisticação das práticas médicas (avanços tecnológicos), o envelhecimento demográfico, a generalização das doenças crônicas, uma população cada vez mais informada daquilo que os sistemas de saúde podem e devem providenciar, explicam a escalada nos custos de saúde ocorridos nas duas últimas décadas.

A presença no setor da saúde de todas as falhas que tipificam o sistema de mercado impedem o mecanismo de preços de desempenhar o seu papel sinalizador. Isso justifica a necessidade de racionamento na medida em que uma procura de cuidados de saúde não condicionada pelo preço enfrenta uma oferta de cuidados de saúde condicionada por considerações de custos. Sob essas condições a procura pelos serviços de saúde suplantará sempre a sua oferta. Os responsáveis políticos por sistemas de saúde publicamente financiados vêem-se, assim, obrigados a atribuir prioridades relativas a diferentes serviços de saúde e a diferentes doentes, prática que na literatura da economia da saúde se designa como racionamento ao nível macro e micro, respectivamente. 
O estabelecimento de prioridades não é assunto novo na área da saúde, mas é um tema com uma importância crescente. A combinação de recursos escassos com procura crescente instigou os decisores políticos a encarar este assunto de forma mais direta que no passado, tendo como resultado um apelo a um racionamento mais explícito.

Tradicionalmente, as abordagens implícitas dominaram a tomada de decisões no setor da saúde. Nesses modelos, os prestadores de cuidados de saúde decidem sem referência a quaisquer critérios publicamente definidos. A vantagem desse tipo de racionamento é o de conferir maior flexibilidade ao estabelecimento de prioridades e afetação dos recursos, embora seja criticado por desencadear decisões ineficientes e ineficazes. As listas de espera são um dos melhores exemplos do estabelecimento implícito de prioridades e têm-se tornado norma em várias tipologias de tratamentos devido à falta de equipamentos e/ou recursos humanos qualificados. O resultado é uma deterioração da condição de saúde do doente, ao ponto de, por vezes, a aplicação da intervenção deixar de fazer sentido. Estudos de opinião indicam que a existência de listas de espera constitui a principal queixa dos indivíduos que se revelam insatisfeitos com o sistema de saúde 1. Adicionalmente, resultados de um inquérito aplicado a seis estados membros da União Européia (Alemanha, França, Itália, Holanda, Reino Unido e Suécia) denotam que o tempo de espera é o critério privilegiado pela maioria dos indivíduos de todos os estados membros para proceder à priorização entre doentes 2 .

O racionamento explícito envolve o estabelecimento de prioridades por meio de um processo claro, transparente e respeitando critérios publicamente definidos. A necessidade de um racionamento mais transparente traduziu-se na procura de novos instrumentos, a serem usados em paralelo com as tradicionais listas de espera e discrição clínica, enquanto métodos para o estabelecimento de prioridades.

A emergência do racionamento explícito é exemplificada pelas experiências de alguns países, nomeadamente, Nova Zelândia, Holanda, Noruega, Suécia, Reino Unido e o estado norteamericano de Oregon. Em qualquer desses países, e desde meados dos anos 80 , que a temática do estabelecimento de prioridades na saúde ocupa um lugar de destaque na agenda política. Contudo, a variedade de abordagens utilizadas deixa antever que o desenvolvimento e implementação da priorização explícita é uma atividade difícil e controversa. Não só foram criticados alguns elementos específicos do processo de priorização explícita como, ainda, diversos teóricos defendem o racionamento implícito alegando que o estabelecimento explícito de prioridades é politicamente impraticável e incapaz de levar em consideração os diversos contextos em que as intervenções de saúde podem, potencialmente, ser oferecidas.

A dificuldade inerente a qualquer uma dessas reformas está no que Okun 3 formalizou como trade-off clássico da economia - entre eficiência e distribuição. Promover uma distribuição dos recursos mais igualitária que a prosseguida, de forma natural, pelos mercados requer, geralmente, tornar os mercados menos eficientes.

Tradicionalmente, a distribuição ocupou, no setor dos cuidados de saúde, um lugar de primazia relativamente à eficiência. O princípio da universalidade, ao defender que todos os cidadãos, sem exceção, devem estar cobertos por esquemas de promoção e proteção na saúde, realça o objetivo da eqüidade sobre o da eficiência. O princípio da solidariedade reforça a preponderância da distribuição sobre a eficiência ao decretar o não racionamento pelo preço.

Quando da institucionalização dos sistemas de saúde a prossecução da eficiência não era um objetivo prioritário. A ineficiência dos sistemas de saúde era tolerada desde que ficasse garantido que todos os indivíduos fossem tratados de forma igual. Porém, a escalada dos custos e a conseqüente escassez dos recursos obrigaram os decisores políticos a repensar as questões da eficiência, transportando para a área da saúde o conflito entre os objetivos da eqüidade e da eficiência. O trade-off emerge sempre que a prossecução da eqüidade resulta numa afetação dos recursos a serviços onde o custo de obter um determinado benefício excede o de afetações alternativas. Contudo, enquanto a eficiência é um conceito claramente definido e capaz de ser medido por meio de, por exemplo, técnicas de avaliação econômica, a eqüidade é um critério altamente subjetivo que reflete valores, considerações éticas e normas sociais.

A literatura da economia da saúde avança duas respostas para minimizar o problema associado ao conflito entre os objetivos da eficiência e da distribuição. Uma das medidas propostas consiste na aposta em novos instrumentos que suportem a tomada de decisões, como sejam, a aposta na medicina baseada na evidência. A outra proposta, consagra um alargamento do debate em torno do estabelecimento de prioridades a todos os autores sociais interessados, particularmente à sociedade em geral. Ainda que a incorporação da sociedade no processo de priorização tenha as suas limitações, parece existir um consenso generalizado entre os de- 
cisores políticos de que a sua participação revestirá um dos maiores inputs do processo de afetação dos recursos 4,5,6,7.

Uma importante motivação neste contexto reside no fato de que as escolhas no setor dos cuidados de saúde envolvem julgamentos de valor sobre a prioridade relativa atribuída a diferentes objetivos e serviços, o que pressupõe que as escolhas sejam informadas pelas preferências da comunidade para que sejam aceitas pelos sujeitos que virão a ser afetados por elas. Adicionalmente é de se esperar que as preferências pelos cuidados de saúde variem não só no nível individual como também no nível cultural e, como tal, o sucesso de uma política de priorização dos cuidados de saúde depende da incorporação dos valores e aspectos culturais da sociedade a que respeita.

\section{Resumo}

O racionamento explícito dos cuidados de saúde é um dos temas mais importantes em discussão nos meios acadêmicos e políticos nos países desenvolvidos e em desenvolvimento. Os artigos apresentados neste Fórum propõem-se a abordar algumas das questões suscitadas por essa problemática. A abordagem é multidisciplinar percorrendo as complexas questões da ética e a contribuição da economia para a reflexão. As análises revelam as especificidades associadas à mudança de uma abordagem implícita de racionar os cuidados de saúde, tradicionalmente dominante nos sistemas de saúde, para um método sistemático e explícito de priorização, em geral, e a potencial incompatibilidade entre os objetivos da eficiência e da eqüidade nas políticas de saúde, em particular. As reflexões do Fórum estão diretamente relacionadas com as correntes discussões em torno das questões "Por que racionar os cuidados de saúde?" e "Como racionar os cuidados médicos?", presentes em todo o mundo.

Assistência à Saúde; Sistemas de Saúde; Planejamento em Saúde

\section{Referências}

1. Cutler D. Equality, efficiency and market fundamentals: the dynamics of International MedicalCare Reform. J Econ Lit 2002; 40:881-906.

2. Mossialos E, King D. Citizens and rationing: analysis of a European survey. Health Policy 1999; 49:75-135.

3. Okun A. Equality and efficiency: the bog trade-off. Washington DC: Brookings; 1975.

4. Bjork S. Ethical and medical basis of health care rationing. In: Spilker B, editor. Quality of life and pharmacoeconomics in clinical trials. Philadelphia: Lippincot-Raven Publishers; 1996. p. 952-71.

5. Klein R, Day P, Redmayne S. Managing scarcity. Buckingham: Open University Press; 1996.

6. Lomas J. Reluctant rationers: public input to health care priorities. J Health Serv Res Policy 1997; 2:103-11.

7. Robinson R. Rationing health care: a national framework and local discretion. J Health Serv Res Policy 1997; 2:67-70.

Recebido em 07/Nov/2007 Aprovado em 10/Jan/2008 